\title{
RESEARCH ARTICLE Allelic Diversity of OsGW5.1 Regulating Grain Width in Rice
}

\author{
Bharathi Ayyenar, Ameena Premnath, Sudhakar D* and \\ Raveendran Muthurajan* \\ Department of Plant Biotechnology, Centre for Plant Molecular Biology and \\ Biotechnology, Tamil Nadu Agricultural University, Coimbatore - 641003.
}

Corresponding author mail id: raveendrantnau@gmail.com; dsudhakar@hotmail.com

\begin{abstract}
Rice is the staple food for more than half of the global population and rice production has to be increased by at least $50 \%$ during 2030 to meet the requirements of the rapidly increasing population. Rice yield is determined by several quantitative traits viz. number of productive tillers, panicle length, number of grains per panicle, grain size, and photosynthetic efficiency. Grain size is a major determinant of rice yield and it is primarily governed by grain length, grain width, and grain thickness. Several candidate genes modulating yield components have been discovered and put into breeding applications. OsGW5.1 (LOC_Os05g25350), encoding for a receptor-like kinase is reported to alter grain width in rice. Advancements in genomics and re-sequencing of 3000 rice genotypes paved way for measuring allelic diversity of putative candidate genes, identification of elite haplotypes, and developing functional markers for breeding applications. In this study, the allelic diversity of OsGW5.1 was analyzed in a set of 151 IRRI-3K panel lines. Eight non-synonymous SNPs were observed and haplotype analysis identified four haplogroups of OsGW5.1. Differences in grain width of the different haplogroups were tested by Dunnet's test. Results revealed that haplotype $1(\mathrm{H} 1)$ and haplotype $2(\mathrm{H} 2)$ showed a significant difference in grain width. KIKUBA (haplogroup 1) was found to possess greater grain width $(3.62 \mathrm{~mm})$ whereas NS1515 (haplotype 2) possessed a slender grain type $(1.88 \mathrm{~mm})$. Identified superior donors possessing elite haplotypes of GW5.1 may be utilized in haplotypebased breeding to develop next generation tailor-made high yielding rice varieties with desired grain size.
\end{abstract}

Keywords: Rice; Grain Width; Allelic Diversity; Haplotype Analysis 


\section{INTRODUCTION}

Rice, one of the most important staple food crop species, is consumed by half of the world's population, particularly in Asia. By 2050, the world's population is predicted to exceed 9.1 billion which requires a simultaneous increase in rice production (Hibberd et al., 2008). Rice productivity has undergone two major leaps viz. first during 1960's through the introduction of semi-dwarfism and secondly during the 1980's through the introduction of hybrids. After that, no major breakthrough in rice yields has been achieved. A number of issues, including water scarcity, soil salinity, disease, climate change, and reduced arable land area have indicated exacerbated food shortages over the next 50 years, demanding immediate improvement in crop production (Zhang, 2007). Any further increase in rice production has to overcome challenges viz. yield plateau, shrinking natural (land and water) resources, and increased occurrence of abiotic stresses, pests, and diseases due to changing climate (Khush et al., 2005). Designing high-yielding rice genotypes adapted to diverse environments depends on the exploitation of genetic resources through phenomics and well knitted genomics-assisted breeding tools. In this study, attempts were made to compile information on various yield genes in rice and survey the allelic diversity of key candidate genes. Literature survey enabled identification of 189 genes related to grain yield attributes and 63 genes regulating grain quality traits. Identification of favorable alleles associated with yield traits may accelerate haplotype based breeding in rice.

An ideal rice cultivar should have high grain yield potential with improved grain shape, nutritional value, disease resistance, and stress tolerance (Rosegrant and Cline, 2003). Rice grain size is a significant trait influencing rice yield and quality.It is also influenced by three geometrical dimensions including grain length, width and thickness with a wide range of variation (Li et al., 2019). Domestication indicators include reduced nucleotide diversity and changed allele frequency in domestication loci. Thus, bridging the molecular study of gene function and domestication research requires a thorough understanding of the molecular basis for natural variation in domesticated features (Purugganan, 2019).

Re-sequencing of $3 \mathrm{~K}$ diverse rice germplasm lines enabled identification and exploring allelic/haplotype variations and thus harnessing genetic diversity (Abbai et al., 2019). Ultimately, this paved way for the identification of novel donors and novel alleles associated with the traits of interest, which can in turn be deployed in crop improvement (Varshney et al., 2018). In this context, the $3 \mathrm{~K}$ RG re-sequencing project holds great promise for harnessing genetic diversity in rice (Li et al., 2014). The identified superior versions of candidate genes could be combined via the recently established, fast and robust 'haplotype assembly' concept (Bevan et al., 2017). For grain width, the gene GW5.1 was encoding a receptor-like kinase (LOC_Os05g25350) was selected (Zhang et al., 2021). The mutant gw5.1 lines showed wider grain width and the lines which harbor the GW5.1 gene produced narrow grains (slender grain type). Allelic diversity of OsGW5.1 was measured using appropriate statistical tools and results are discussed.

\section{MATERIAL AND METHODS}

A set of 151 diverse rice accessions from IRRI-3K Panel was assembled (Table 1) and evaluated during kharif 2020-21. The grain width of 151 accessions was measured using Vernier caliper. Ten grains per genotype were used for measurement of grain width. Measured data were subjected to descriptive statistics analysis using Minitab 19 and frequency distribution and box plot graphs were created (Allen, 2019).

Nucleotide polymorphisms existing in the GW5.1 (LOC_Os05g25350) were visualized using SNP seek database and haplotype analysis was performed by downloading the allelic variants of the GW5.1 gene in PLINK format (Weeks, 2010). Haploview 4.2 software was used to create haplotype groups and linkage disequilibrium blocks containing allelic variation, with settings such as a HW p-value (Hardy-Weinberg $p$ value) of 0.001 , a minimum genotype percent of 75 , and a minimum minor allele frequency of 0.001(Barrett et al., 2005). Dunnett's test, performed with Minitab 19 Statistical Software, revealed significant differences between the generated haplotype groups (Allen, 2019).

\section{RESULTS AND DISCUSSION}

Descriptive statistics analysis defined the measures of variability among the 151 accessions. The coefficient of variation was found to be moderately high, indicating there is abundant variation in the population and thus selection of suitable donors for the respective trait can be done with the genotypes available (Table 2). The range of grain width varied from $1.88 \mathrm{~mm}$ to $3.62 \mathrm{~mm}$, with an average of 2.65 $\mathrm{mm}$, according to the box plot curve (Fig1a). According to the histogram, the population has a normal distribution (Fig1b).

All the 151 germplasm lines were clustered into 4 haplogroups based on the sequence diversity of OsGW5.1. Eight non-synonymous SNPs identified in the OsGW5.1 (LOC_Os05g25350) were identified. The 
haplotype group viz. H1, H2, H3 and H4 were found to contain 121, 22, 7 and 1 genotype, respectively. The H4 haplotype showed a heterozygous allele and it was not taken for further analysis. Eight SNPs (Table 3) from GW5.1 gene were employed in the construction of four haplotypes using haploview, as illustrated in Fig. 2a. The linkage disequilibrium block depicts the alleles at nearby positions that can occur on the same haplotype (Fig. 2b). In contrast to Mendel's law of independent assortment, linkage disequilibrium refers to the non-random association of alleles in a locus. The SNP site 10514718976 and 10514720069 had the highest LD r2 value which indicates (Fig 2b-Values inside the blocks) high correlation (98) between these two sites.

From Table 4, it was understood that haplotype H1 contained maximum number of genotypes (121) followed by H2 (22) and H3 (7). H4 was represented by only one genotype that showed heterozygous allele and was not included in the phenotypic analysis. The maximum grain width was observed in haplotype 1 (3.62 $\mathrm{mm})$, followed by H3 $(2.97 \mathrm{~mm})$ and H2 $(2.83 \mathrm{~mm})$. From the Dunnett's test results, it was observed that there is a significant difference between $\mathrm{H} 2-\mathrm{H} 1$ ( $\mathrm{p}$ values <0.05) (Table 5 and Figure 3). KIKUBA was identified to possess a wider grain type $(3.62 \mathrm{~mm}$ ) observed in the $\mathrm{H} 1$ haplotype group and NS1515 had a narrow grain type (slender, $1.88 \mathrm{~mm}$ ) present in the haplotype group $\mathrm{H} 2$. From this study, it was found that the genotype, NS1515 can be used as a donor for the development of rice genotypes with slender grain type. Similarly, Ramasamy et al. (2021) and Sundaramoorthy et al. (2022) identified superior haplotypes for An-1 and Gn1a genes, respectively.

\section{CONCLUSION}

The study resulted in unravelling the allelic variations in the GW5.1 gene with the help of 151 genotypes from 3K RG panel, and their grouping based on haplotyping identified a superior haplotype $\mathrm{H} 2$ which can be exploited in allele mining and plant breeding programmes. Thus, haplotype-based breeding is expected to aid in the development of high-quality rice varieties with desired grain width to fulfill the growing demands of the rice consuming population.

\section{Funding and Acknowledgment}

The authors acknowledge the receipt of seeds.

\section{Ethics statement}

No specific permits were required for the described field studies because no human or animal subjects were involved in this research.

\section{Originality and plagiarism}

This is original research work and any work and/or words of others, has been appropriately cited.

\section{Consent for publication}

All the authors agreed to publish the content.

\section{Competing interests}

There were no conflict of interest in the publication of this content.

\section{Data availability}

All the data of this manuscript are included in the MS. No separate external data source is required. If anything is required from the MS, certainly, this will be extended by communicating with the corresponding author through corresponding official mail; raveendrantnau@gmail.com; dsudhakar@hotmail.com

\section{Author contributions}

Idea conceptualization - MR, Experiments - BA, Guidance - MR, DS, Writing original draft - BA, AP; Writingreviewing \& editing - BA, AP, DS, MR.

\section{REFERENCES}

Abbai, R., Singh, V. K., Nachimuthu, V. V., Sinha, P., Selvaraj, R., Vipparla, A. K., Singh, A. K., Singh, U. M., Varshney, R. K. and A. Kumar. 2019. Haplotype analysis of key genes governing grain yield and quality traits across $3 K$ RG panel reveals scope for the development of tailor-made rice with enhanced genetic gains. Plant biotechnology journal, 17(8): 1612-1622. 
Allen, T. T. 2019. Introduction to Engineering Statistics and Lean Six Sigma (London: Springer) Software overview and methods review: Minitab 575-600.

Barrett, J. C., Fry, B., Maller, J. and M. J. Daly. 2005. Haploview: analysis and visualization of LD and haplotype maps. Bioinformatics, 21: 263-265.

Bevan, M. W., Uauy, C., Wulff, B. B., Zhou, J., Krasileva, K. and M. D. Clark. 2017. Genomic innovation for crop improvement. Nature, 543(7645): 346-354.

Hibberd, J. M., Sheehy, J. E. and J. A. Langdale. 2008. Using C4 photosynthesis to increase the yield of ricerationale and feasibility. Curr. Opin. Plant Biol., 11:228-231.

Khush, G. S. 2005. What it will take to feed 5.0 billion rice consumers in 2030. Plant Mol. Biol., 59: 1-6.

Li, J. Y., Wang, J. and R. S. Zeigler. 2014. The 3,000 rice genomes project: new opportunities and challenges for future rice research. Gigascience, 3(1): 2047-217X.

Li, N., Xu, R. and Y. Li. 2019. Molecular networks of seed size control in plants. Annu. Rev. Plant Biol., 70: 435-463.

Priya, R. S., Kalaimagal, T., Rajeswari, S., Prasanth, R. A. and M. Raveendran. 2021. Allele mining for the grain number gene I in rice (Oryza sativa L.). Electronic Journal of Plant Breeding, 12(3):772-779.

Purugganan, M. D. 2019. Evolutionary insights into the nature of plant domestication. Curr. Biol., 29: R705-R714.

Rosegrant, M. W. and S. A. Cline. 2003. Global food security: challenges and policies. Science, 302: 19171919.

Sundaramoorthy, M., Ramasamy, S. P., Rajagopalan, V. R., Ramalingam, A. P., Ayyenar, B., Mohanavel, V., Narayanan, M. B. and R. Muthurajan. 2022. Pilot scale genome wide association mapping identified novel loci for grain yield traits in rice. Plant Physiol. Rep., https://doi.org/10.1007/ s40502-021-00641-w.

Varshney, R. K., Singh, V. K., Kumar, A., Powell, W. and M. E. Sorrells. 2018. Can genomics deliver climatechange ready crops?. Current opinion in plant biology, 45: 205-211.

Weeks, J. P. 2010. Plink: An R package for linking mixed-format tests using IRT-based methods. Journal of Statistical Software, 35(12): 1-33.

Zhang, J., Zhang, D., Fan, Y., Li, C., Xu, P., Li, W., Sun, Q., Huang, X., Zhang, C., Wu, L., Yang, H., Wang, S., Su, X., Li, X., Song, Y., Wu, M., Lian, X. and Y. Li. 2021. The identification of grain size genes by RapMap reveals directional selection during rice domestication. Nature Communications, 12(1): 118.

Zhang, Q. 2007. Strategies for developing Green Super Rice. Proc. Natl. Acad. Sci. USA., 104: 1640216409. 

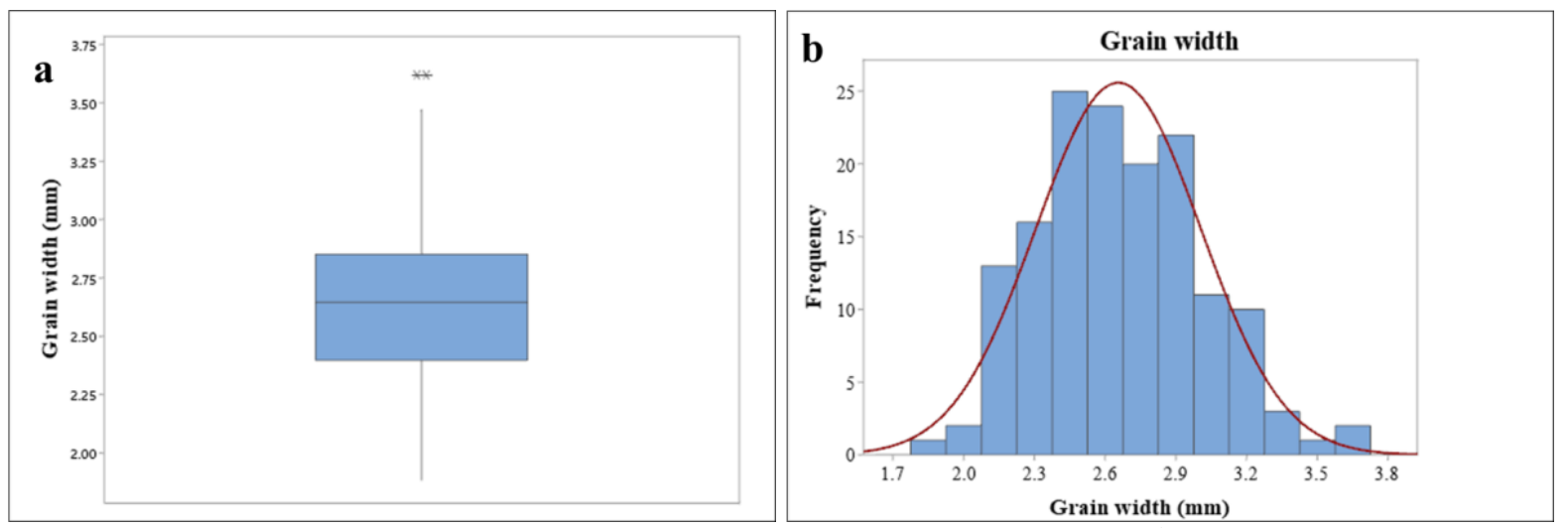

Figure 1. a) Boxplot for grain width; b) Frequency distribution curve for grain width

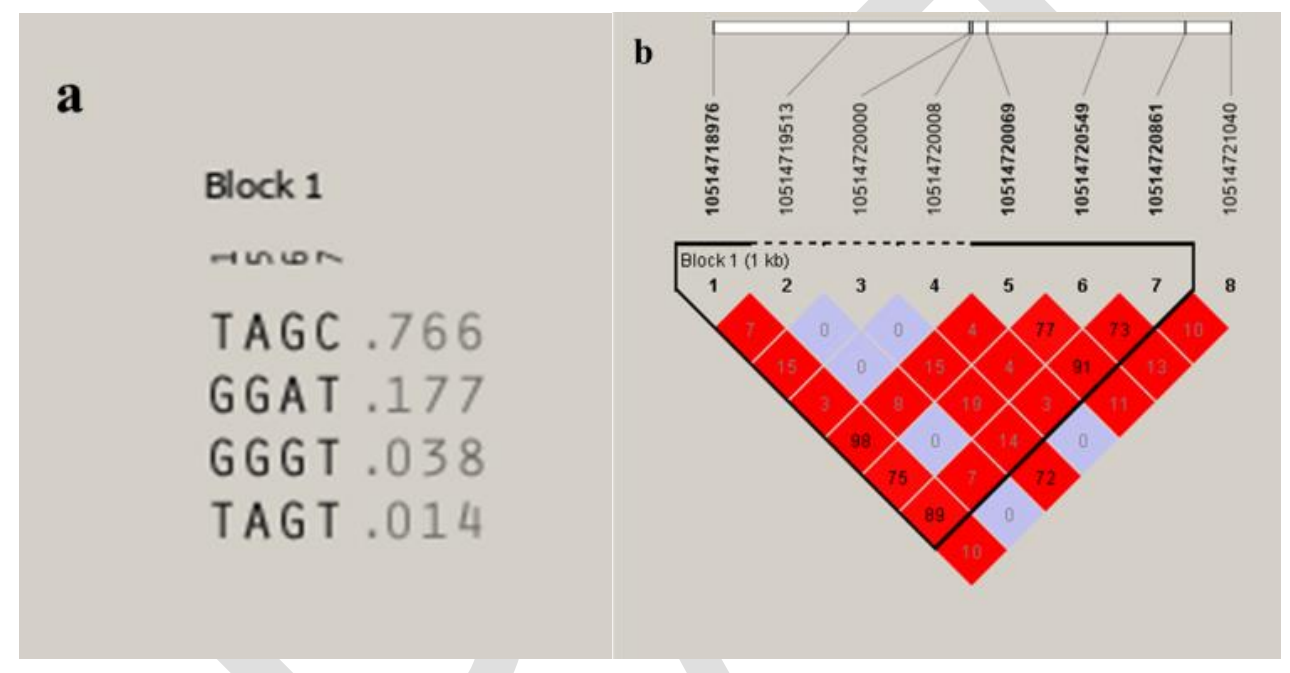

Figure 2. a) Formation of haplotype groups based on allelic variation; b) Linkage Disequilibrium (LD) block of GW5.1 gene for 150 genotypes

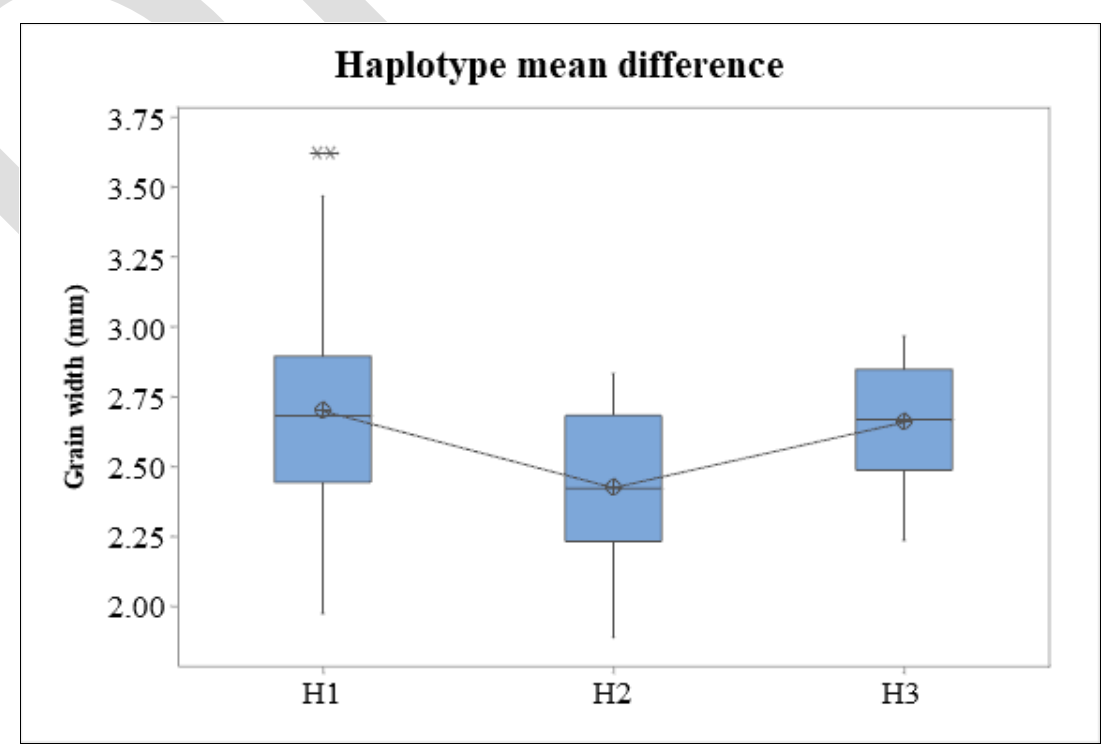

Figure 3. Box plot curve for different haplotypes indicating significant difference by Dunnett's test 
Table 1. List of genotypes used in the present study and their haplotype groups

\begin{tabular}{|c|c|c|c|c|c|c|c|c|}
\hline $\begin{array}{l}\text { S. } \\
\text { No. }\end{array}$ & Accessions & $\mathrm{H}$ & $\begin{array}{l}\text { S. } \\
\text { No. }\end{array}$ & Accessions & $\mathrm{H}$ & $\begin{array}{l}\text { S. } \\
\text { No. }\end{array}$ & Accessions & H \\
\hline 1 & CX145 & $\mathrm{H} 1$ & 51 & IRIS_313-8595 & $\mathrm{H} 1$ & 101 & IRIS_313-11885 & H3 \\
\hline 2 & CX94 & $\mathrm{H} 1$ & 52 & IRIS_313-8638 & $\mathrm{H} 1$ & 102 & IRIS_313-11126 & $\mathrm{H} 1$ \\
\hline 3 & IRIS_313-8288 & $\mathrm{H} 1$ & 53 & IRIS_313-8509 & $\mathrm{H} 2$ & 103 & IRIS_313-10880 & $\mathrm{H} 1$ \\
\hline 4 & IRIS_313-8265 & $\mathrm{H} 1$ & 54 & IRIS_313-15902 & $\mathrm{H} 1$ & 104 & IRIS_313-11256 & $\mathrm{H} 1$ \\
\hline 5 & IRIS_313-10403 & $\mathrm{H} 1$ & 55 & IRIS_313-10298 & $\mathrm{H} 1$ & 105 & IRIS_313-11262 & $\mathrm{H} 1$ \\
\hline 6 & IRIS_313-10423 & $\mathrm{H} 1$ & 56 & IRIS_313-10353 & $\mathrm{H} 1$ & 106 & IRIS_313-11263 & $\mathrm{H} 1$ \\
\hline 7 & IRIS_313-7668 & $\mathrm{H} 1$ & 57 & IRIS_313-11744 & $\mathrm{H} 1$ & 107 & IRIS_313-11266 & $\mathrm{H} 1$ \\
\hline 8 & IRIS_313-7684 & $\mathrm{H} 2$ & 58 & IRIS_313-11377 & $\mathrm{H} 1$ & 108 & IRIS_313-11271 & H1 \\
\hline 9 & IRIS_313-8067 & $\mathrm{H} 2$ & 59 & IRIS_313-11624 & $\mathrm{H} 1$ & 109 & IRIS_313-11308 & $\mathrm{H} 1$ \\
\hline 10 & IRIS_313-7650 & $\mathrm{H} 2$ & 60 & IRIS_313-10664 & $\mathrm{H} 1$ & 110 & IRIS_313-11310 & $\mathrm{H} 1$ \\
\hline 11 & IRIS_313-7799 & $\mathrm{H} 1$ & 61 & IRIS_313-11812 & H1 & 111 & IRIS_313-11192 & $\mathrm{H} 1$ \\
\hline 12 & IRIS_313-8703 & $\mathrm{H} 1$ & 62 & IRIS_313-10924 & $\mathrm{H} 1$ & 112 & IRIS_313-11241 & $\mathrm{H} 2$ \\
\hline 13 & IRIS_313-8660 & $\mathrm{H} 1$ & 63 & IRIS_313-11656 & H1 & 113 & IRIS_313-11358 & $\mathrm{H} 1$ \\
\hline 14 & IRIS_313-8697 & $\mathrm{H} 1$ & 64 & IRIS_313-11852 & H1 & 114 & IRIS_313-10986 & $\mathrm{H} 1$ \\
\hline 15 & IRIS_313-9427 & $\mathrm{H} 1$ & 65 & IRIS_313-11853 & H3 & 115 & IRIS_313-10775 & $\mathrm{H} 1$ \\
\hline 16 & IRIS_313-9574 & $\mathrm{H} 1$ & 66 & IRIS_313-11692 & H1 & 116 & IRIS_313-11327 & $\mathrm{H} 1$ \\
\hline 17 & IRIS_313-9067 & $\mathrm{H} 1$ & 67 & IRIS_313-11854 & $\mathrm{H} 1$ & 117 & IRIS_313-10974 & $\mathrm{H} 1$ \\
\hline 18 & IRIS_313-9503 & $\mathrm{H} 1$ & 68 & IRIS_313-11671 & H1 & 118 & IRIS_313-10754 & $\mathrm{H} 1$ \\
\hline 19 & IRIS_313-9348 & $\mathrm{H} 1$ & 69 & IRIS_313-11676 & $\mathrm{H} 1$ & 119 & IRIS_313-11076 & $\mathrm{H} 1$ \\
\hline 20 & IRIS_313-10113 & $\mathrm{H} 1$ & 70 & IRIS_313-11721 & H1 & 120 & IRIS_313-10555 & $\mathrm{H} 1$ \\
\hline 21 & IRIS_313-10047 & $\mathrm{H} 1$ & 71 & IRIS_313-10769 & $\mathrm{H} 1$ & 121 & IRIS_313-11418 & $\mathrm{H} 2$ \\
\hline 22 & IRIS_313-9302 & $\mathrm{H} 1$ & 72 & IRIS_313-10966 & H1 & 122 & IRIS_313-11242 & $\mathrm{H} 1$ \\
\hline 23 & IRIS_313-10224 & H3 & 73 & IRIS_313-11802 & $\mathrm{H} 1$ & 123 & IRIS_313-11399 & $\mathrm{H} 1$ \\
\hline 24 & IRIS_313-10167 & $\mathrm{H} 2$ & 74 & IRIS_313-11505 & H3 & 124 & IRIS_313-11141 & $\mathrm{H} 1$ \\
\hline 25 & IRIS_313-9968 & $\mathrm{H} 1$ & 75 & IRIS_313-11506 & $\mathrm{H} 1$ & 125 & IRIS_313-11372 & $\mathrm{H} 1$ \\
\hline 26 & IRIS_313-9709 & $\mathrm{H} 2$ & 76 & IRIS_313-11867 & $\mathrm{H} 1$ & 126 & IRIS_313-11181 & $\mathrm{H} 1$ \\
\hline 27 & IRIS_313-9696 & $\mathrm{H} 1$ & 77 & IRIS_313-11814 & $\mathrm{H} 1$ & 127 & IRIS_313-11254 & $\mathrm{H} 1$ \\
\hline 28 & IRIS_313-9605 & $\mathrm{H} 1$ & 78 & IRIS_313-11543 & $\mathrm{H} 1$ & 128 & IRIS_313-10433 & $\mathrm{H} 1$ \\
\hline 29 & IRIS_313-8956 & $\mathrm{H} 2$ & 79 & IRIS_313-11577 & $\mathrm{H} 1$ & 129 & IRIS_313-10822 & $\mathrm{H} 1$ \\
\hline 30 & IRIS_313-9325 & $\mathrm{H} 1$ & 80 & IRIS_313-11234 & H3 & 130 & IRIS_313-10753 & $\mathrm{H} 1$ \\
\hline 31 & IRIS_313-9320 & $\mathrm{H} 1$ & 81 & IRIS_313-10609 & $\mathrm{H} 1$ & 131 & IRIS_313-10897 & $\mathrm{H} 1$ \\
\hline 32 & IRIS_313-9841 & $\mathrm{H} 1$ & 82 & IRIS_313-11869 & $\mathrm{H} 2$ & 132 & IRIS_313-11793 & $\mathrm{H} 2$ \\
\hline 33 & IRIS_313-10000 & $\mathrm{H} 1$ & 83 & IRIS_313-11784 & H1 & 133 & IRIS_313-11467 & $\mathrm{H} 1$ \\
\hline 34 & IRIS_313-9160 & $\mathrm{H} 1$ & 84 & IRIS_313-11760 & $\mathrm{H} 2$ & 134 & IRIS_313-11899 & $\mathrm{H} 2$ \\
\hline 35 & IRIS_313-10054 & $\mathrm{H} 2$ & 85 & IRIS_313-11545 & $\mathrm{H} 2$ & 135 & IRIS_313-11808 & $\mathrm{H} 1$ \\
\hline 36 & IRIS_313-9469 & H3 & 86 & IRIS_313-11811 & $\mathrm{H} 1$ & 136 & IRIS_313-11954 & $\mathrm{H} 1$ \\
\hline
\end{tabular}




\begin{tabular}{cllllllll}
\hline $\begin{array}{c}\text { S. } \\
\text { No. }\end{array}$ & Accessions & H & $\begin{array}{c}\text { S. } \\
\text { No. }\end{array}$ & Accessions & H & $\begin{array}{c}\text { S. } \\
\text { No. }\end{array}$ & Accessions & H \\
\hline 37 & IRIS_313-10171 & H1 & 87 & IRIS_313-11446 & H1 & 137 & IRIS_313-8349 & H1 \\
38 & IRIS_313-10333 & H1 & 88 & IRIS_313-11638 & H1 & 138 & IRIS_313-8493 & H2 \\
39 & IRIS_313-10016 & H1 & 89 & IRIS_313-11644 & H1 & 139 & IRIS_313-9329 & H1 \\
40 & IRIS_313-10260 & H3 & 90 & IRIS_313-11762 & H2 & 140 & IRIS_313-11758 & H1 \\
41 & IRIS_313-10046 & H1 & 91 & IRIS_313-11761 & H2 & 141 & IRIS_313-12280 & H2 \\
42 & IRIS_313-10300 & H1 & 92 & IRIS_313-10458 & H1 & 142 & IRIS_313-11509 & H1 \\
43 & IRIS_313-10314 & H1 & 93 & IRIS_313-10955 & H2 & 143 & IRIS_313-11914 & H2 \\
44 & IRIS_313-10396 & H1 & 94 & IRIS_313-11820 & H1 & 144 & IRIS_313-11225 & H2 \\
45 & IRIS_313-10402 & H1 & 95 & IRIS_313-10717 & H1 & 145 & IRIS_313-11554 & H1 \\
46 & IRIS_313-9227 & H1 & 96 & IRIS_313-12296 & H1 & 146 & IRIS_313-10441 & H1 \\
47 & IRIS_313-8932 & H1 & 97 & IRIS_313-10715 & H1 & 147 & IRIS_313-10900 & H1 \\
48 & IRIS_313-9116 & H1 & 98 & IRIS_313-11521 & H1 & 148 & IRIS_313-11251 & H1 \\
49 & IRIS_313-9433 & H1 & 99 & IRIS_313-11548 & H1 & 149 & IRIS_313-10690 & H1 \\
50 & IRIS_313-9986 & H1 & 100 & IRIS_313-11507 & H1 & 150 & IRIS_313-10628 & H1 \\
& & & & & & 151 & IRIS_313-8293 & H4 \\
\hline
\end{tabular}

Table 2. Descriptive statistics for OsGW5.1 among the study population

\begin{tabular}{lc}
\hline \multicolumn{1}{c}{ Statistics } & Total population \\
\hline Range & $1.88-3.62 \mathrm{~mm}$ \\
Mean & $2.65 \mathrm{~mm}$ \\
Median & $2.64 \mathrm{~mm}$ \\
SE Mean & 0.03 \\
CV $(\%)$ & 13.21 \\
\hline
\end{tabular}

Table 3. Details of identified significant alleles

\begin{tabular}{cccccc}
\hline $\begin{array}{c}\text { Marker } \\
\text { number }\end{array}$ & SNP site & Position & HW pval & MAF & Alleles \\
\hline 1 & 10514718976 & 14718976 & $8.84 \mathrm{E}-34$ & 0.218 & T:G \\
2 & 10514719513 & 14719513 & $1.15 \mathrm{E}-08$ & 0.022 & $\mathrm{~A}: \mathrm{T}$ \\
3 & 10514720000 & 14720000 & $3.91 \mathrm{E}-09$ & 0.04 & $\mathrm{~A}: \mathrm{T}$ \\
4 & 10514720008 & 14720008 & $4.38 \mathrm{E}-05$ & 0.011 & G:A \\
5 & 10514720069 & 14720069 & $5.53 \mathrm{E}-35$ & 0.215 & A:G \\
6 & 10514720549 & 14720549 & $1.53 \mathrm{E}-29$ & 0.182 & G:A \\
7 & 10514720861 & 14720861 & $1.36 \mathrm{E}-28$ & 0.232 & C:T \\
8 & 10514721040 & 14721040 & $1.88 \mathrm{E}-06$ & 0.03 & A:G \\
\hline
\end{tabular}


Table 4. Statistical difference between haplotype groups

\begin{tabular}{lccc}
\hline \multicolumn{1}{c}{ Statistics } & H1 (121) & H2 (22) & H3 (7) \\
\hline Range & $1.93-3.62 \mathrm{~mm}$ & $1.88-2.83 \mathrm{~mm}$ & $2.23-2.97 \mathrm{~mm}$ \\
Mean & $2.7 \mathrm{~mm}$ & $2.42 \mathrm{~mm}$ & $2.66 \mathrm{~mm}$ \\
Median & 2.68 & $2.42 \mathrm{~mm}$ & $2.67 \mathrm{~mm}$ \\
SE Mean & 0.03 & 0.05 & 0.09 \\
CV (\%) & 13.12 & 11.11 & 9.47 \\
\hline
\end{tabular}

Table 5. Dunnett's Simultaneous Tests for Level Mean-Control Mean

\begin{tabular}{cccc}
\hline Difference of levels & Mean difference & t value & p value \\
\hline $\mathrm{H} 2-\mathrm{H} 1$ & -0.2747 & -3.49 & 0.001 \\
$\mathrm{H} 3-\mathrm{H} 1$ & -0.04 & -0.31 & 0.942 \\
\hline
\end{tabular}

